\title{
STUDY ON THE SRID EVALUATION FRAMEWORK OF AGRICULTURAL ENTERPRISES IN CHINA
}

\author{
Maohua Li*, Zoltán Zéman
}

Szent István University, Gödöllő, Hungary

In recent years, the exposure of a series of environmental pollution incidents has made people focus on the corporate social responsibility (CSR). Social responsibility information disclosure system is, perfect or not, directly related to the success or failure of environmental protection. Application of environmental social responsibility can be more effective to do this work. The purpose of this paper is to construct an evaluation framework to help judge the quality of social responsibility information disclosure (SRID). Taking Chinese agricultural enterprises as a sample, this paper finishes two studies on the SRID evaluation framework social of agricultural enterprises. Firstly, through literature review and oral theme encoding, this paper establishes the SRID evaluation framework of agricultural enterprises for the first time at home and abroad. Secondly, the framework we established is verified through the expert opinion method, exploratory and confirmatory factor analysis. The SRID evaluation framework of agricultural enterprises we build includes fore elements and 12 indicators. The fore elements are content quality, total quality, presentation quality, utility quality, and the 12 indicators are objectivity, correctness, credibility, relevance, completeness, sufficiency, definition, intelligibility, conciseness, timeliness, adaptability, testability. The evaluation framework of our research gives a standard to evaluate the SRID, and can help to understand the quality of SRID of agricultural enterprises, and then evaluate how the agricultural enterprises fulfill their environmental and social responsibility. And through the evaluation of SRID by our framework, we can find the strength and weakness of the SRID and give advice to improve the quality of SRID.

Keywords: environmental responsibility, agriculture enterprise, information disclosure, evaluation framework

\section{Introduction}

Social responsibility information disclosure (SRID) is the information of the enterprise management authorities to disclose the integrity, rationality and validity of the social responsibility according to a certain standard (Dawkins, 2016). SRID, carried out by agricultural enterprises, is based on the original evaluation criteria, to determine the establishment of the sound social responsibility, to evaluate its efficiency of CSR, and to issue the assessment report. The existence of this mechanism can help to find the problem in the process of establishing and running the agricultural enterprises social responsibility (Kolk, 2016).

This paper is mainly based on self evaluation report of the social responsibility. The research on the evaluation framework of SRID of agricultural enterprises should first consider whether it meets the requirements of laws and regulations, and then evaluate the usefulness to the investors and the internal managers. The real purpose of SRID is through accurate and detailed disclosure of agricultural enterprises to help information users understand the intentions of agricultural enterprises, transfer the good status of agricultural enterprises, and reduce the misunderstandings in the process of information disclosure (Saguy, 2016). With the continuous development of market economy, the governance structure of agricultural enterprises is constantly improving; the information needed is more and more comprehensive, which requires both financial information and non-financial information, and includes both quantitative information and qualitative information (Jha and Cox, 2015). Because of the counterfeit component of quantitative financial information, the users pay more and more attention to non financial information. However, qualitative and non financial information is relatively hard to get and analyze, so that quantifying the qualitative information is an urgent (Xueming and Shuili, 2015).

The main purpose of this paper is to set up a set of indicators to evaluate SRID of agricultural enterprises, in order to solve the problem that SRID is lack of indicators to evaluate, and to help the previous user to get rid of only using some financial indicators.

\section{Material and methods}

In the process of SRID evaluation framework construction, in order to ensure the reliability and accuracy of the results, this paper selects 200 Chinese $^{1}$ agricultural enterprises from Shenzhen and Shanghai Stock Exchange as the research sample. Social responsibility report belongs to the "control self appraisal (CSA)", which is a proactive corporate self-examination (Sandoval, 2015). This paper selects 200 samples, and the time range of the samples is from 2009 to 2015. Thus, there is no conflict between the old and the new accounting system in China, which reflects the timeliness of this study. Since the preparation of this paper began in 2015, the reports in 2015 of the samples were selected for the first half year. Subject to the limitations of the study conditions and the actual consideration of the workload, the number of samples selected should not be too large. This paper selects 200 agricultural enterprises in China.

During the verification of the framework, we took 560 Chinese agricultural enterprises as the questionnaire sample, to issue the questionnaires to the relevant agricultural enterprises. 500 electronic copies of the questionnaire were issued by the internet, and 360 electronic copies were recovered. A total of 60 questionnaires were issued by printing and 60 printed copies were recovered. The details are shown in table 1 . This paper randomly selects $40 \%$ of them to do exploratory factor analysis, and the remaininig $60 \%$ are used to do confirmatory factor analysis.

When constructing the framework, this paper mainly studies the self evaluation reports of SRID of agricultural enterprises in China. Through the sample research with oral theme encoding, this paper analyzes the social

1 In order to ensure the reliability and accuracy of the results, here we select total 200 listed agricultural enterprises except ST companies, because we can only get CSR self evaluation reports of listed companies from Shenzhen and Shanghai Stock Exchanges. And to verify the evaluation framework, we select 560 enterprises (including listed and unlisted companies) which can make the samples more representative. 
Table 1 Descriptive statistics of Questionnaires of 60 Chinese agricultural enterprises

\begin{tabular}{|l|c|c|}
\hline Classification & Number & Percentage \\
\hline Farming & 14 & $23.34 \%$ \\
\hline Forestry & 5 & $8.33 \%$ \\
\hline Animal Husbandry & 8 & $13.33 \%$ \\
\hline Side-line Production & 11 & $18.33 \%$ \\
\hline Fishery & 13 & $21.67 \%$ \\
\hline Integrated Agriculture & 9 & $15.00 \%$ \\
\hline Total & 60 & $100 \%$ \\
\hline
\end{tabular}

responsibility self evaluation reports of agricultural enterprises, and finds out the evaluation characteristics of SRID. And then the evaluation framework is obtained through the frequency analysis, consistency test and reliability test.

In order to verify the SRID evaluation framework, we use two methods. First, the expert opinion method is used to verify the framework. Secondly, this paper uses factor analysis to further verify the SRID framework.

Firstly, the SRID evaluation framework is verified by the expert opinion method. In order to verify the SRID evaluation framework of agricultural enterprises, we use the traditional expert opinion method to verify the validity of the evaluation framework. We have invited 8 experts from 20 agricultural enterprises in China, including corporate executives, financial executives, and business executives. The author is the host of the interview, and two students are its recorders. In order to ensure the success of interview, we first compile the outline of an interview, and prepare two recording pens, two notebooks and some pens.

Secondly, the evaluation framework is verified by factor analysis. According to the evaluation framework established, this paper prepares the SRID evaluation framework self-rating questionnaire, and each indicator is subdivided into polygraph questions and

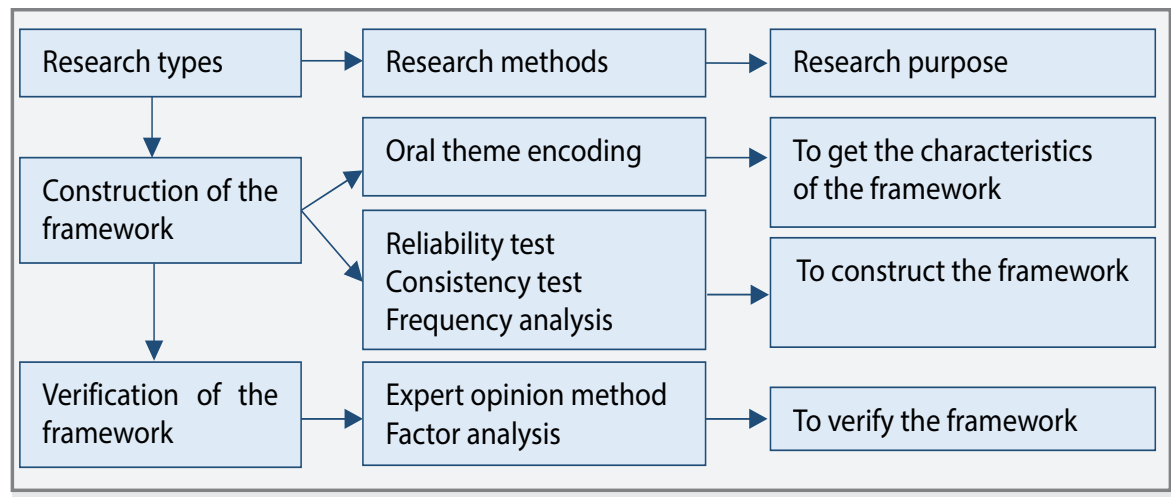

Figure 1 The structure of research

Table 2 Frequency of the oral theme encoding $(n=19)$

\begin{tabular}{|l|c|c|l|c|c|}
\hline Name & $\mathrm{T}_{1}$ & $\mathrm{~T}_{2}$ & Name & $\mathrm{T}_{1}$ & $\mathrm{~T}_{2}$ \\
\hline Objectivity 01 & 198 & 199 & Definition 11 & 298 \\
\hline Correctness 02 & 90 & 117 & Intelligibility 12 & 213 & 197 \\
\hline Credibility 03 & 177 & 179 & Conciseness 13 & 28 & 31 \\
\hline Appropriateness 04 & 62 & 79 & Applicability 14 & 45 & 78 \\
\hline Cost-benefits 05 & 156 & 115 & Operability 15 & 31 & 77 \\
\hline Relevance 06 & 178 & 181 & Timeliness 16 & 15 & 38 \\
\hline Completeness 07 & 35 & 77 & Adaptability 17 & 180 & 186 \\
\hline Sufficiency 08 & 57 & 77 & Testability 18 & 81 & 54 \\
\hline Acceptability 09 & 51 & 91 & Designability 19 & 123 & 145 \\
\hline Concreteness 10 & 188 & 185 & & & \\
\hline
\end{tabular}

verification questions. The whole questionnaire contains the total of 24 questions. Each question is divided into five grades, and the grade is defined by $1-5$. According to the data source of this paper, we deal with the data obtained from the paper questionnaire and the network questionnaire separately. We use SPSS 22.0 software and LISREL8.70 software to analyze the data collected with Bartlett's test and factor analysis.

The structure and methods of the research are shown in figure 1.

\section{Hypothesis}

At present, the CSR self evaluation report is the only way to disclose CSR, and also the only way in which we can get CSR information. The purpose of this paper is to construct the SRID evaluation framework with the help of CSR self evaluation report. The quality of the CSR information disclosure is reflected by the CSR self assessment report. So we make the assumption:

There is a positive relation between SRID and CSR self evaluation report.

\section{Framework construction}

This paper encodes reports that we select according to the social responsibility. To ensure the results are real and effective, this paper first pre-encodes, and then uses the 200 social responsibility reports for the official encoding. Finally, found the following characteristics of SRID, including: objectivity, correctness, credibility, appropriateness, cost-benefits, relevance, completeness, sufficiency, acceptability, concreteness, definition, intelligibility, conciseness, applicability, operability, timeliness, adaptability, testability, and designability.

Following the analysis program of oral theme encoding (OTE), the author and the independent coders holding the same social responsibility reports encode at the same time, and make a detailed record. First they carry out the training of pre-encoding, and then carry out the formally independent encoding. Each report is required to conduct twice independent encoding, and we record the frequency of each encoding and other data, and process the data.

The first step is to study the social responsibility report, and it is also a very important and key step. The analysis results of the oral theme encodings will directly affect the frequency analysis, consistency test and reliability test.

\section{Frequency analysis}

This paper, through the analysis of the oral theme encoding of the social responsibility report, gets the characteristics of the evaluation, and finds out 
the specific indicators. We record the frequency and other related data of every encoding. This paper selects 19 characteristics from independent encoding, and records the frequency of each characteristic. The frequency of encoding reflects the tendency of the agricultural enterprises to disclose the social responsibility information, and also provides the basis for the specific research framework. The encoding statistics are seen in table 2.

In table 2, there are 9 characteristics that appear to have a relatively high frequency between encoding group 1 and encoding group 2. The difference between them is not significant, so the statistical error is acceptable. But there is lack of persuasion and reliability to construct SRID evaluation framework only from coders' view, therefore this paper takes consistency test and reliability test to the oral theme encoding.

\section{Consistency test}

Before the establishment of the evaluation framework, the internal consistency of both independent encoding and reliability level is tested on the basis of the consistency test.

This paper uses the Agreement Category (CA) to test the consistency of the statistical results of the oral theme encoding. And the calculating formula of the Agreement Category is:

$$
C A=S \div\left(T_{1}+T_{2}\right)
$$

where:

$T_{1} \quad$ - the number of encoding by the first coder

$T_{2} \quad$ - the number of encoding by the second coders

$S \quad$ - the same number for the two encodings

\section{Reliability test}

Reliability test is the test of the stability and reliability of the results obtained by this research. The reliability includes external and internal reliability (Akira, 2015). External reliability is measured on the degree of consistency of encoding at different time. The reliability test of this research is mainly the internal reliability. The modern detection of internal reliability is to calculate the Cronbach's Alpha. The greater Cronbach's Alpha is, the higher internal consistency is. The study of American statisticians Hair and Anderson (1998) shows that Cronbach's Alpha is greater than 0.7 for higher reliability, in between 0.6 and 0.7 also can be accepted. In this study, we use the method of Cronbach's Alpha to test the reliability of 19 characteristics. Reliability test formula is:

$$
\alpha=\frac{N \times C A}{[1+(N-1) \times C A]}
$$

where:

$N$ - the number of coders, in this study, the number of coders is 2, so $N=2$

According to the two above formulas, this paper takes the consistency test and reliability test to the encoding. The results of consistency test and reliability test are shown in Table 3.

From table 3, we can see that the consistency coefficient of the encoding is between 0.41510.9617 , and arrange of consistency coefficient is larger. The reliability coefficient of the encoding is in the range between $0.5867-0.9805$. This shows that consistency and encoding reliability of the two coders are relatively high, which provide a scientific basis and a certain degree of reliability for the results of this study.

Based on the frequency analysis, consistency test and reliability test of the oral theme encoding, this paper constructs SRID evaluation framework. This study deletes the characteristic whose $\alpha$ is less than 6 or whose CA is less than 5 . And the framework includes 12 indicators: objectivity, correctness, credibility, relevance, completeness, sufficiency, definition, intelligibility, conciseness, timeliness, adaptability, testability. And we classify them by their meanings into 4 parts which are shown in table 4.

\section{Verification of the framework Expert opinion method}

Firstly, the host introduces the purpose and principle of the interview, the meaning of SRID, the importance and significance of establishing the SRID evaluation framework. And then the interview is taken on according to the outline. After the interview, we summarize the recording and notes taken by the two students.

Through the repeated confirmation of the statistics and the contents of the recording and notes, the conclusion of expert opinion method is

\begin{tabular}{|c|c|c|c|c|c|}
\hline NO. & $T_{1}$ & $T_{2}$ & $S$ & $C A$ & $\alpha$ \\
\hline 1 & 198 & 199 & 170 & 0.8564 & 0.9227 \\
\hline 2 & 90 & 117 & 80 & 0.7729 & 0.8719 \\
\hline 3 & 177 & 179 & 160 & 0.8989 & 0.9467 \\
\hline 4 & 62 & 79 & 35 & 0.4965 & 0.6635 \\
\hline 5 & 156 & 115 & 63 & 0.4649 & 0.6348 \\
\hline 6 & 178 & 181 & 165 & 0.9192 & 0.9579 \\
\hline 7 & 35 & 77 & 32 & 0.5714 & 0.7273 \\
\hline 8 & 57 & 77 & 46 & 0.6866 & 0.8142 \\
\hline 9 & 51 & 91 & 35 & 0.4930 & 0.6604 \\
\hline 10 & 188 & 185 & 79 & 0.4236 & 0.5951 \\
\hline 11 & 298 & 210 & 185 & 0.7283 & 0.8428 \\
\hline 12 & 213 & 197 & 189 & 0.9220 & 0.9594 \\
\hline 13 & 28 & 31 & 20 & 0.6780 & 0.8081 \\
\hline 14 & 45 & 78 & 29 & 0.4715 & 0.6409 \\
\hline 15 & 31 & 77 & 23 & 0.4259 & 0.5974 \\
\hline 16 & 15 & 38 & 11 & 0.4151 & 0.5867 \\
\hline 17 & 180 & 186 & 176 & 0.9617 & 0.9805 \\
\hline 18 & 81 & 54 & 51 & 0.7556 & 0.8608 \\
\hline 19 & 123 & 145 & 56 & 0.4179 & 0.5895 \\
\hline
\end{tabular}

Table 3 Results of consistency test and reliability

Table 4 SRID evaluation framework of Chinese agricultural enterprises

\begin{tabular}{|l|l}
\hline Content Quality & objectivity, correctness, credibility \\
\hline Total Quality & relevance, completeness, sufficiency \\
\hline Presentation Quality & definition, intelligibility, conciseness \\
\hline Utility Quality & timeliness, adaptability, testability \\
\hline
\end{tabular}


Table 5 Bartlett's Test of Sphericity and KMO of Social self-assessment questionnair

\begin{tabular}{|l|c|}
\hline KMO & 0.971 \\
\hline \multirow{3}{*}{ Bartlett's Test of Sphericity } & Approx Chi-Square 6435.75 \\
\cline { 2 - 2 } & df 496 \\
\cline { 2 - 2 } & Sig 0.000 \\
\hline
\end{tabular}

Table 6 Exploratory factor analysis of Social self-assessment questionnaire

\begin{tabular}{|c|c|c|c|c|c|}
\hline \multirow[t]{2}{*}{ Items } & \multicolumn{4}{|c|}{ Factors loading } & \multirow{2}{*}{$\begin{array}{l}\text { Factor common } \\
\text { degrees }\end{array}$} \\
\hline & 1 & 2 & 3 & 4 & \\
\hline A01 & 0.42 & 0.44 & 0.45 & 0.48 & 0.43 \\
\hline A02 & 0.53 & 0.45 & 0.53 & 0.58 & 0.55 \\
\hline A03 & 0.43 & 0.42 & 0.45 & 0.43 & 0.44 \\
\hline A04 & 0.56 & 0.54 & 0.44 & 0.57 & 0.57 \\
\hline A05 & 0.44 & 0.56 & 0.46 & 0.57 & 0.47 \\
\hline A06 & 0.64 & 0.56 & 0.65 & 0.46 & 0.55 \\
\hline B01 & 0.35 & 0.46 & 0.56 & 0.47 & 0.45 \\
\hline B02 & 0.44 & 0.46 & 0.56 & 0.57 & 0.41 \\
\hline B03 & 0.45 & 0.45 & 0.49 & 0.48 & 0.48 \\
\hline B04 & 0.48 & 0.60 & 0.53 & 0.53 & 0.52 \\
\hline B05 & 0.56 & 0.54 & 0.55 & 0.51 & 0.51 \\
\hline B06 & 0.49 & 0.47 & 0.47 & 0.47 & 0.45 \\
\hline C01 & 0.56 & 0.54 & 0.42 & 0.41 & 0.45 \\
\hline CO2 & 0.56 & 0.57 & 0.45 & 0.51 & 0.52 \\
\hline $\mathrm{CO3}$ & 0.54 & 0.53 & 0.54 & 0.49 & 0.47 \\
\hline C04 & 0.45 & 0.41 & 0.47 & 0.48 & 0.46 \\
\hline $\cos$ & 0.45 & 0.46 & 0.54 & 0.53 & 0.52 \\
\hline CO6 & 0.53 & 0.54 & 0.55 & 0.43 & 0.54 \\
\hline D01 & 0.55 & 0.56 & 0.60 & 0.61 & 0.46 \\
\hline D02 & 0.55 & 0.56 & 0.53 & 0.43 & 0.44 \\
\hline D03 & 0.55 & 0.54 & 0.60 & 0.49 & 0.47 \\
\hline D04 & 0.57 & 0.52 & 0.48 & 0.48 & 0.46 \\
\hline D05 & 0.45 & 0.46 & 0.43 & 0.41 & 0.44 \\
\hline D06 & 0.56 & 0.44 & 0.46 & 0.57 & 0.49 \\
\hline Characteristic Root & 12.87 & 1.92 & 1.40 & 1.87 & - \\
\hline Cumulative Proportion in ANOVA & 48.63 & 15.70 & 13.25 & 9.12 & - \\
\hline
\end{tabular}

Table 7 NFI of confirmatory factor analysis of Social self-assessment questionnaire

\begin{tabular}{|c|c|c|c|c|c|c|c|c|}
\hline$x^{2}$ & $d f$ & $x^{2} / d f$ & GFI & AGFI & RMR & RMSEA & NFI & NNFI \\
\hline 1212.25 & 496 & 2.74 & 0.89 & 0.85 & 0.49 & 0.485 & 0.92 & 0.95 \\
\hline
\end{tabular}

summarized. The majority of the experts believe that a set of relatively sound SRID of agricultural enterprises should meet this evaluation framework, which includes: objectivity, correctness, credibility, relevance, completeness, sufficiency, definition, intelligibility, conciseness, timeliness, adaptability, testability. During the free discussion, the experts point out that the evaluation framework is only a specimen; each agricultural enterprise should set up its own SRID evaluation framework according to its own development stage and financial situation. Through the analysis of the content of speech and the attitude of the experts, the evaluation framework of this paper has been recognized by the experts. In order to further guarantee the results of the research, we take the questionnaire survey and factor analysis to verify the evaluation framework.

\section{Factor analysis}

In order to check whether it is suitable to take factor analysis, we take the Bartlett's Test of Sphericity and KMO. The result is shown in table 5.

From the table 5, we can see that the KM0 of samples is 0.971 . The value of KMO means that there is no significant difference between different items of the questionnaire and the data from questionnaire is suitable for the next factor analysis. In the Bartlett's Test of Sphericity, the Approx Chi-Square is 6435.75, $d f$ is 496, and significance is 0.000 , which also means the items of the questionnaire are independent and the data is suitable for factor analysis.

\section{Exploratory factor analysis}

Exploratory factor analysis (EFA) is a technique used to find out the essential structure of multivariate observation variables and to reduce the dimension of the variables. As a result, EFA can be integrated into a small number of core factors with complex relationships. The principal component analysis method is used to carry out the Promax skew rotation. The analysis result is shown in the table 6:

From the table 6, we see that after we select the factor loading $<0.3$ and the factor common degrees $<0.4$, all the polygraph questions are removed, because the factor loading is less than 0.3 or factor common degree is less than 0.4 . The factor loading of the entire remained element is greater than 0.4, except B01, and the factor common degree of them is greater than 0.4 . The result of table 6 means that the total cumulative proportion in ANOVA of 4 factors is $86.70 \%$. Except the project B01, other projects are greater than 0.40 , the specific results are shown in table 6. In this case, in order to confirm the result of research, we continue to take confirmatory factor analysis.

\section{Confirmatory factor analysis}

For the rest of the questionnaires, the LISREL8.7 software is used for confirmatory factor analysis. Through the confirmation factor analysis, we further test the validity of SRID framework, and want to verify the assumption above that there is a positive relation between SRID and CSR self evaluation report. This paper uses the LISREL 8.7 software and uses maximum likelihood estimation (ML) to take the test. The result of confirmatory factor analysis is in the table 7 : 
To further verify the factor structure of the questionnaire, this paper uses the maximum fitting estimate to analyze the covariance matrix of each item of the SRID evaluation framework. From table 7, it can be seen that $x^{2} / d f$, the value of fitting function, is 2.74 . And according to the statistical principle, the value of $x^{2} / d f$ is between 2 and 5 , so the evaluation framework can be accepted. The values of GFI, AGFI, NFI and NNFI are close to 0.90 , and the RMR and RMSEA are close to 0.50 . These results show that the model-fitting degree of the SRID evaluation framework is better, and the structure validity of the self rating questionnaire is ideal.

\section{Results and discussion}

The construction of SRID evaluation framework based on the social responsibility report is the main research, and through the factor analysis, expert opinion method, our research verifies thescientific nature of the research results. But through the unremitting efforts of scholars in the academic circles, the research results continue to emerge, and some scholars do not agree with the results obtained by the social responsibility report. However, this does not affect the significance and value of this paper. The internal management and external information users of agricultural enterprises can understand the relevant information of agricultural enterprises through the application of the ideas and results of this paper.

CSR self evaluation report is the only way that we can get the information about the SRID. Through the oral theme encoding and related analysis, we construct the SRID evaluation framework. And then during the verification of the framework, especially the questionnaire, we find that the enterprises with complete, detailed CSR self evaluation report perform better in the progress of questionnaire. This means that the company with highquality self evaluation report will have a high-quality SRID. This verifies the hypothesis above.

There are many methods that can be used to construct the evaluation framework, and we choose the most mature method that is the oral theme encoding. In order to ensure the caution of our study, we take the reliability and validity test based on the frequency analysis. The SRID evaluation framework established on this basis is more scientific and accurate. Of course, the coders with different ability and understanding of the self evaluation report will get different encoding results. Therefore, in order to ensure the accuracy of the encoding results, this study used two coders to encode at the same time.

During the process of verification of the SRID evaluation framework, two methods are used, namely expert opinion method and factor analysis. Generally speaking, one method used for verification is enough. However, this paper does exploratory factor analysis and confirmation factor analysis based on the expert opinion method, which reflects the scientific caution of the researcher. Through the verification of SRID framework, we not only verify the accuracy of the SRID evaluation framework, but also verify the assumption that there is a positive relation between SRID and CRS self evaluation report.

In the capital market, the investors always and only use the CSR self evaluation report to read the situation of the SRID, and then to judge the fulfillment of the CSR. During this case, the quality of SRID is not related to the interest of the investors, but also relates all the stakeholders' interest in the society. Among these (enterprises, investors and stakeholders), the SRID plays a very important role as the media for information transmission. So this paper has a great significance in the capital market.

There are still many problems about the SRID evaluation framework, such as how to use this framework to evaluate the real enterprise? What is the weight of each item? These questions are the directions of our following research. For instance, next paper will use AHP method to weight all the items of the SRID evaluation framework which will make our evaluation framework more useful and practical. Because of the limit of author's energy and paper's length, we cannot finish all possibilities in one work.

\section{Acknowledgements}

This work is carefully repaired by Dr. habil. Zéman Zoltán of Szent István university and sponsored by China Scholarship Council. At last, I want to thank two anonymous referees for their constructive feedback.

\section{Reference}

AKIRA, 0. 2015. Corporate Social Responsibility or Payoff Asymmetry? A Study of an Endogenous Timing Game. In Southern Economic Journal, vol. 81, 2015, no. 2, pp. 457-473.

BLUMNÉ, BÁN, E. - ZÉMAN, Z. 2014. Controlling a vezetés szolgálatában. In Történő fejlődés, perspektívák, vol. 1, 2014, no. 2, pp. 439-447.

DAWKINS, CEDRIC, E. 2016. A Test of Labor Union Social Responsibility. In Business \& Society, vol. 55, 2016, no. 2, pp. 214-245.

GE, W. - LIU, M. 2015. Corporate social responsibility and the cost of corporate bonds. In Journal of Accounting \& Public Policy, vol. 34, 2015, no. 6, pp. 597-624.

JHA, A. - COX, J. 2015. Corporate Social Responsibility and Social Capital. In Journal of Banking and Finance, vol. 60, 2015, no. 12, pp. 252-270.

KIM, S. H. 2015.Who Is Responsible for a Social Problem? News Framing and Attribution of Responsibility. In Journalism \& Mass Communication Quarterly, vol. 92, 2015, no. 3, pp. 554-558.

KOLK, Ans. 2016. The Social Responsibility of International Business: From Ethics and the Environment to CSR and Sustainable Development. In Journal of World Business, vol. 51, 2016, no. 1, pp. 23-34.

LUO, X. - DU, S. 2015. Exploring the relationship between corporate social responsibility and firm innovation. In Marketing Letters, vol. 26, 2015, no. 4, pp. 703-714.

SAGUY, I. S. 2016. Challenges and opportunities in food engineering: modeling, virtualization, open innovation and social responsibility. In Journal of Food Engineering, vol. 176, 2016, no. 1, pp. 2-8.

SANDOVAL, M. 2015. From CSR to RSC: A Contribution to the Critique of the Political Economy of Corporate Social Responsibility. In Review of Radical Political Economics, vol. 47, 2015, no. 4, pp. 608-624.

ZÉMAN, Z. - MAHESH, K.S - BÁRCZI, J. 2014. A múködési, pénzügyi és stratégiai kockázatok feltérképezése, mérése és a kockázatjelentések tartalmi összefüggései. In Controller Info, vol. 1, 2014, no. 12, pp. 2-6.

\section{Contact address}

Maohua Li, PhD, CMA, Lecturer, Szent István Egyetem, Faculty of Economics and Social Sciences, H-2100 Gödöllő, Páter Károly u. 1. GTK, 胥 +3670358 90 62, e-mail: maohua.li@qq.com 